\title{
Aplikasi Wakaf Indonesia Berbasis Blockchain
}

\author{
Sarah Suryaningsih ${ }^{1}$, Yoga Afrizal Riandika ${ }^{2}$, Arifa Nur Hasanah ${ }^{3}$, Sigit Anggraito ${ }^{4}$ \\ ${ }^{1,2,3}$ Program Studi Teknik Informatika, Universitas Telkom \\ ${ }^{4}$ PT Telekomunikasi Indonesia, Tbk \\ email: sarahsy@student.telkomuniversity.ac.id ${ }^{1}$, \\ yogaafrizal@student.telkomuniversity.ac.id ${ }^{2}$, arifahnur@student.telkomuniversity.ac.id ${ }^{3}$, \\ sigitanggra@gmail.com ${ }^{4}$
}

(Received: 17 Juli 2020 / Accepted: 27 November 2020 / Published Online: 20 Desember)

\begin{abstract}
Abstrak
Wakaf memiliki peranan penting di salah satu aspek dalam islam pada sektor perekonomian. Sebagai dokumen dan bukti, wakaf dicatat oleh nazhir (penerima, penjaga, yang memelihara wakaf) dengan kertas dan tanda terima. hal itu sangat rentan terhadap kehilangan data wakaf yang dikarenakan hanya didokumentasikan dengan kertas yang mudah hilang ataupun rusak. Berdasarkan permasalahan tersebut maka di kembangkanlah aplikasi wakaf berbasis teknologi blockchain yang bertujuan untuk mengamankan data pencatatan transaksi wakaf agar tidak hilang ataupun diretas oleh orang yang tidak bertanggung jawab, selain itu untuk menambah tingkat efektifitas dalam melaksanakan transaksi wakaf dari sisi wakif (orang yang mewakafkan harta bendanya) ataupun dari sisi nazhir (orang yang menjaga harta wakaf). Metode pengumpulan data yang digunakan pada artikel ini yaitu kuesioner dan juga wawancara, sementara untuk pembangunan aplikasi menggunakan metode waterfall. artikel ini menegaskan bahwa wakaf dapat disimpan lebih baik lagi dalam upaya pengamanan dan keamanan data yang dilakukan secara digital lewat website dan juga aplikasi android. Hasil pengujian yang digunakan mendapatkan hasil total 95\% dengan kriteria sangat layak, dengan demikian hasil pengujian dari aplikasi ini memiliki nilai yang sangat layak untuk diaplikasikan pada transaksi wakaf yang tersedia karena memberikan keamanan dan keefektifan kepada penggunanya.
\end{abstract}

\section{Kata kunci: Blockchain, Database, Wakaf}

\begin{abstract}
Waqf has an important role in one aspect of Islamic in the economic sector. For document and evidence, waqf noted by nazir (receiver, guard, who maintains waqf) with paper and receipt. That is very vulnerable to losing waqf data which is because it is only documented by paper which is easy to lose or damaged. Based on that problem, then the waqf application based blockchain technology was developed which Aims to securing record data of waqf transaction so as not to be lost or hacked by irresponsible people, other than that for increase effectiveness in executing waqf transaction from wakif (a person who donates his property) side and nazhir (receiver, guard, who maintains waqf) side. The data collection methods used in this article are questionnaires and also interviews. This article confirms that waqf could be stored even better in security effort and saving data which is done digitally via website and android application. The results of the research which got a total result 95\% with very feasible criteria, therefore the result of this research from this application have a very feasible score to be implemented for available waqf transaction because it has given more secure and effectiveness for the user.
\end{abstract}

\section{Keywords: Blockchain, Database, Waqf}

\section{PENDAHULUAN}

Saat ini banyak orang yang sudah berwakaf menggunakan aplikasi yang sudah tersedia di internet ataupun smartphone, pada awalnya praktik wakaf dilakukan dengan mencatat data 
wakaf yang diberikan oleh wakif, namun cara itu sangatlah rentan terhadap kehilangan ataupun kecurangan data seperti Masjid Jamik al-Ihsan di Puyung Lombok Tengah yang kehilangan tanah wakafnya. Terdapat database yang dapat mengamankan data dengan efisien dan sulit untuk di retas yaitu blockchain. Blockchain merupakan salah satu teknologi yang krusial dalam mendukung efisiensi dan transparansi sehingga dapat mengantisipasi perubahan dunia yang sangat cepat (Nakasumi, 2017).

Teknologi blockchain ini memiliki sifat yang fleksibel yang mana tidak menutup kemungkinan akan terdapat model blockchain yang lainnya di masa yang akan datang. beberapa jenis blockchain yang sedang berkembang di masa kini yaitu Blockchain tipe publik, tipe konsorsium dan juga blockchain tipe privat (Zhang, Li, Zhao, Zhang, \& Ma, 2019). Jenis - jenis blockchain tersebut memiliki kelebihan dan kekurangannya masing masing. Tipe paling umum yang digunakan yaitu blockchain tipe publik yang memiliki sifat terbuka dan mengawal mula dari blockchain ini harus memiliki kesepakatan dari sejumlah pengguna atau forum online untuk dikerjakan secara bersamaan (Caldiroli et al., 2017; Feng, He, Zeadally, Khan, \& Kumar, 2019; Judmayer et al., 2017). Blockchain konsorsium berbeda dengan tipe publik yang dikerjakan secara bersamaan oleh sejumlah komunitas. model ini dikembangkan secara mandiri oleh sebuah perusahaan, dan dipersiapkan secara matang untuk dipublikasikan. Sedangkan blockchain tipe privat atau tertutup merupakan tipe yang tidak mempublikasikan kode sumbernya ke publik dan proprietary dianggap sebagai hak intelektual, karena sifatnya yang tertutup (Huang et al., 2019; Muzammal, Qu, \& Nasrulin, 2019), jaringan blockchain ini disediakan untuk perusahaan tersebut atau digunakan secara privat saja (Ayed, 2017).

Wakaf merupakan kegiatan keagamaan yang dilakukan oleh orang yang beragama islam, kegiatan ini sudah dilakukan turun temurun sejak zaman kenabian hingga saat ini pun kegiatan wakaf masih banyak dilakukan oleh kaum muslimin. Wakaf dilakukan dengan cara mendatangi KUA dan petugas akan mencatat data data wakaf yang telah diserahkan. Data tersebut berupa kertas yang sangat rentan hilang ataupun rusak. Banyak tanah - tanah wakaf yang akhirnya tidak teridentifikasi sebagai tanah wakaf karna hal tersebut. Data wakaf seharusnya dapat tersimpan dengan kekal dan tidak dapat di ubah. Maka dari itu pembuatan aplikasi ini dilaksanakan untuk menanggulangi permasalahan tersebut. Dengan database blockchain data wakaf akan tersimpan dengan aman dan tidak dapat di ubah (Lee, 2007), karna sifat dari blockchain itu sendiri yaitu tidak dapat dihapus dan tidak dapat di ubah, blockchain (Yu \& Huang, 2018) pun sukar untuk di retas untuk saat ini.

Penelitian ini penting untuk dilakukan karena melihat bagaimana data wakaf pada saat ini rentan terhadap kehilangan dan kecurangan, dengan menggunakan teknologi penyimpanan blockchain ini, data tidak akan hilang untuk selamanya selama internet dan komputer masih tetap ada dan juga data tidak dapat di ubah oleh siapapun. Dari penelitian sebelumnya, penyimpanan dari aplikasi masih menggunakan metode penyimpanan biasa yang rentan terhadap kecurangan dan juga kehilangan. Terdapat keterbatasan dari penelitian sebelumnya disebutkan bahwa salah satu keterbatasan pada penelitian tersebut adalah keterbatasan database sehingga data yang digunakan merupakan data tahun terakhir yang dapat diakses (Berakon \& Irsad, 2017). Namun Dengan menggunakan teknologi penyimpanan blockchain, data dapat tersimpan dengan kekal dan juga sangat sukar untuk di retas ataupun di ubah.

Tujuan dari penelitian ini adalah untuk membangun dan juga mengembangkan aplikasi transaksi wakaf dengan menggunakan database blockchain untuk mengamankan data pencatatan transaksi wakaf yang dilakukan pada aplikasi wakaf, selain itu untuk menambah tingkat efektivitas dalam melaksanakan wakaf karena wakaf dilakukan secara online dengan menggunakan aplikasi android ataupun website. Terdapat 2 jenis aplikasi wakaf yang dibuat, yaitu aplikasi android, dan aplikasi website. Aplikasi android merupakan aplikasi yang dibentuk untuk melakukan wakaf uang dan melihat saham Syariah CWLS (Fahmi, Sugiarto, 
Winarno, Sumpeno, \& Purnomo, 2018). Wakaf uang dilakukan dengan menggunakan blockchain yang terintegrasi dengan dua aplikasi web yang dibuat (Fahmi et al., 2017). Aplikasi website yang pertama digunakan untuk melakukan wakaf bangunan dan wakaf juga wakaf tanah, aplikasi web ini dikelola oleh KUA untuk melakukan pendaftaran dan transaksi wakaf tanah dan bangunan. sedangkan aplikasi web yang kedua merupakan portal umum yang dapat digunakan dan dilihat oleh masyarakat umum (Pinandito, Az-zahra, Fanani, \& Putri, 2017; Rohmaningtyas, 2017).

\section{METODE}

Dalam pembangunan aplikasi, metode pengembangannya menggunakan metode waterfall. Dengan metode waterfall proses dalam pengembangannya dilakukan secara berurutan sesuai dengan siklus pengembangan yang ada. Kualitas dari sistem yang dihasilkan pun akan baik, sehingga tidak berfokus pada tahapan tertentu. Karena jika tahap 1 belum terselesaikan, maka tahap 2 tidak bisa berjalan dan begitupun seterusnya.

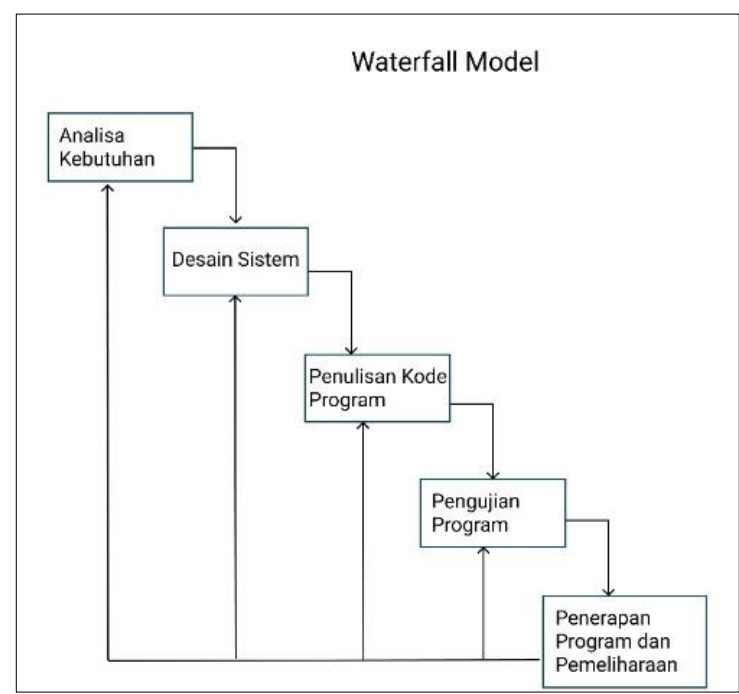

Gambar 1. Metode Waterfall

Sebelum melakukan pembangunan aplikasi terlebih dahulu melakukan analisa kebutuhan. Mengumpulkan data data yang nantinya akan digunakan dalam pembangunan aplikasi. Setelah data terkumpul dilanjutkan ke tahapan desain sistem. Membuat rancangan sistem aplikasi, seperti diagram alir dan design aplikasi. Kemudian mengimplementasikan rancangan sistem ke dalam bentuk aplikasi dengan dilakukannya penulisan kode program. Ketika kode program sudah selesai ditulis, dan aplikasi sudah jadi dilakukan pengujian program. Untuk mengetahui apakah aplikasi yang sudah dibangun memiliki kekurangan atau tidak, dan dilakukannya perbaikan jika terdapat kerusakan atau kekurangan. Selain itu juga untuk menguji apakah aplikasi sudah efektif atau belum. Dalam pembangunan aplikasi, kali ini pengujian aplikasi menggunakan metode alpha dan beta testing. Alpha testing adalah pengujian yang dilakukan oleh user pada lingkungan pengembangan. Alpha testing dilakukan sebelum nantinya akan dirilis untuk pelanggan eksternal. Agar nantinya ketika pelanggan menggunakan system ini tidak kecewa karena masalah cacat atau kegagalan aplikasi. Setelah Alpa Testing selesai dilanjutkan Beta testing. Beta testing untuk melakukan pengecekan terhadap perangkat lunak.

Tahap terakhir adalah penerapan program dan pemeliharaan. Pemeliharan sangat penting untuk menjaga kualitas aplikasi. Selain metode waterfall (Anam \& Anwar, 2020), terdapat metode Blockchain. Blockchain adalah teknologi penyimpanan data yang disimpan secara permanen dalam catatan buku yang berbentuk rantai blok data yang saling terkait yang 
penyimpanannya tersebar. Dalam prose pembangunan aplikasi dalam bidang design, software yang dipakai adalah Adobe Photoshop dan Figma. Adobe Photoshop digunakan dalam membuat icon - icon yang dibutuhkan. Figma adalah salah satu aplikasi yang digunakan oleh UI atau UX designer dalam membuat tampilan antarmuka untuk website ataupun mobile apps. Berbeda dengan Adobe Photoshop, aplikasi Figma memudahkan beberapa designer untuk berkolaborasi dan bekerja tim secara bersama dalam dokumen yang sama serta dapat memberikan komentar, saran, bahkan mengubah rancangan desain yang ada dalam waktu yang bersamaan. Selain itu juga Figma bersifat real time dimana setiap perubahan akan tersimpan secara otomatis.

\section{HASIL DAN PEMBAHASAN \\ Hasil}

Pada bagian ini akan dijelaskan multimedia interaktif pada pembangunan aplikasi Wakaf Indonesia yang berbasis android dan website, aplikasi yang dibangun berdasarkan blockchain yang akan dimanfaatkan untuk berwakaf. Sesuai dengan metode waterfall yang digunakan berdasarkan hasil analisis yang telah dilakukan terbentuklah beberapa tampilan yang sesuai dengan kebutuhan Badan Wakaf Indonesia (BWI) baik untuk tampilan android maupun website. Pada tahap analisis kami memcatat dan memastikan fungsi apa saja yang ingin ditampilkan dalam aplikasi yang dibangun dan setelah itu dibentuklah desain aplikasi yang dibuat cocok dan membantu mempermudah penggunakannya oleh user. Setelah pembuatan desain lalu kami melakukan analisis kepada pihak Badan Wakaf Indonesia apakah desain yang dibangun telah sesuai dengan ekspetasi mereka lalu dilanjutkan ke tahap pembangunan aplikasi berupa penulisan program, hingga setelah itu melakukan testing dan melakukan penerapan terhadap aplikasi yang telah dibangun dan pemeliharaan terhadap aplikasi tersebut. Dan dibawah ini merupakan beberapa tampilan yang akan dibangun untuk aplikasi wakaf berbasis android dan website yang dapat dilihat pada gambar 2 .

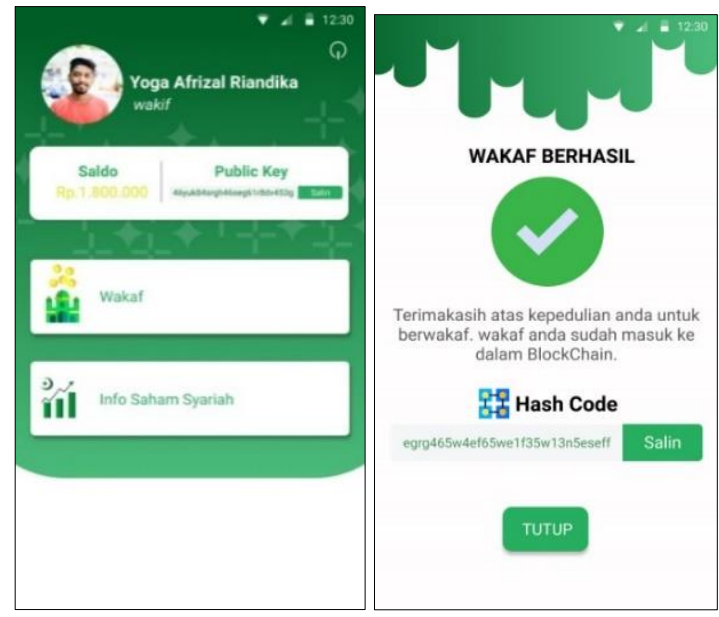

Gambar 2. Tampilan Aplikasi Wakaf berbasis Android

Pada gambar 2 merupakan tampilan menu utama atau home pada aplikasi android yang akan dibangun. Selain itu juga ditampikan user melakukan pembayaran wakaf dan mendapatkan hash code yaitu kode yang didapatkan setiap kali setelah melakukan transaksi dan akan langsung dicatat oleh server dan tidak hanya satu server namun semua server yang terhubung dengan aplikasi android wakaf. 

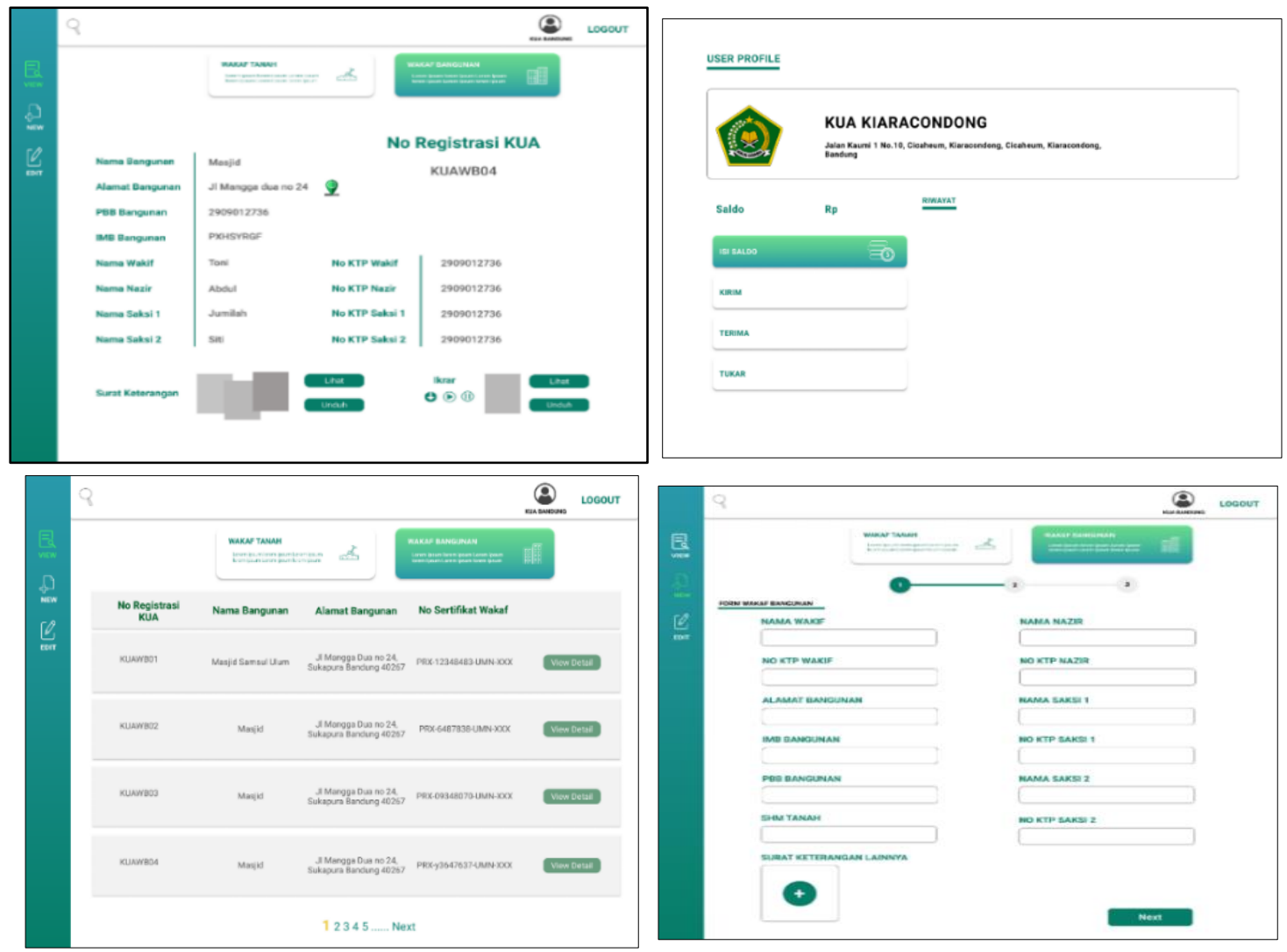

Gambar 3. Tampilan Aplikasi Wakaf Berbasis Website

Pada gambar 3, merupakan tampilan dari aplikasi wakaf berbasis website yang akan dijalankan oleh KUA, dan di khususkan untuk wakaf bangunan dan wakaf tanah. Pada gambar tersebut terdapat tampilan detail dari wakaf bangunan atau tanah yang telah diwakafkan, berisi alamat dan dokumen lainnya. Selain itu, terdapat tampilan profile, dan daftar wakaf yang terdapat pada data KUA, serta tampilan form yang harus diisi oleh wakif dengan bantuan KUA karena tidak dapat dilakukan mandiri oleh sebab itu dibantu oleh pihak KUA. Semua data yang telah tersimpan akan ikut tercatat pada semua server yang tergabung dengan aplikasi wakaf ini sehingga tidak dapat diedit dan dihapus yang merupakan salah satu kelebihan menggunakan blockchain.

\section{Hasil Uji Beta Testing}

Pada tahap uji ahli adalah tahap dimana melakukan pengujian perangkat lunak dengan menggunakan metode Alpha Testing. Alpha testing merupakan metode pengujian pada tahap pengembangan suatu perangkat lunak. Yang menguji kesalahan pada suatu perangkat dan akan diperbaiki setelah itu. Pengujian ini dilakukan sebelum merealisasikan pada lingkungan sebenarnya, dan dalam tahap ini melibatkan beberapa ahli pada bidangnya yaitu Andri Krisdianto. Setelah melakukan Alpha testing maka akan berlanjut dengan pengujian menggunakan Beta testing. Beta testing yaitu melakukan pengecekan terhadap perangkat lunak dan hasil pengujian tersebut dapat dilihat pada tabel 1 dan 2. 
Tabel 1. Hasil Beta Testing 1 pada website Wakaf Indonesia

\begin{tabular}{|c|c|c|c|}
\hline \multirow{2}{*}{ Tombol } & \multirow{2}{*}{ Fungsi } & \multicolumn{2}{|c|}{ Pengujian } \\
\hline & & $\mathrm{Ya}$ & Tidak \\
\hline Tombol Sign Up & Registrasi akun & $\checkmark$ & \\
\hline Tombol Profile & Profile akun & $\checkmark$ & \\
\hline Tombol Logout & Keluar akun & $\checkmark$ & \\
\hline Tombol View & Melihat list data wakaf & $\checkmark$ & \\
\hline Tombol New & Membuat wakaf baru & $\checkmark$ & \\
\hline Tombol Edit & Mengubah data wakaf & $\checkmark$ & \\
\hline Tombol Wakaf Tanah & Pilihan menu pada wakaf tanah & $\checkmark$ & \\
\hline Tombol Wakaf Bangunan & Pilihan menu pada wakaf bangunan & $\checkmark$ & \\
\hline Tombol Upload & Mengunggah file yang dibutuhkan & $\checkmark$ & \\
\hline Tombol Simpan & Menyimpan data & $\checkmark$ & \\
\hline Tombol Search & Mencari data & $\checkmark$ & \\
\hline Tombol Location & Melihat lokasi suatu data pada wakaf & $\checkmark$ & \\
\hline Tombol Lihat & Melihat dokumen wakaf & $\checkmark$ & \\
\hline Tombol Unduh & Mengunduh dokumen wakaf & $\checkmark$ & \\
\hline Tombol Isi Saldo & Mengisi saldo akun & $\checkmark$ & \\
\hline Tombol Kirim & Mengirim saldo akun & $\checkmark$ & \\
\hline Tombol Terima & Menerima saldo akun & $\checkmark$ & \\
\hline Tombol Tukar & Menukar saldo akun & $\checkmark$ & \\
\hline
\end{tabular}

Tabel 2. Hasil Beta Testing 2 pada android Wakaf Indonesia

\begin{tabular}{|c|c|c|c|}
\hline \multirow{2}{*}{ Tombol } & \multirow{2}{*}{ Fungsi } & \multicolumn{2}{|c|}{ Pengujian } \\
\hline & & $\mathrm{Ya}$ & Tidak \\
\hline Tombol Login & Masuk akun ke menu utama & $\checkmark$ & \\
\hline Tombol Lupa Password & Akun lupa password & $\checkmark$ & \\
\hline Tombol Registrasi & Mendaftar akun baru & $\checkmark$ & \\
\hline Tombol Profile & Profile dari akun & $\checkmark$ & \\
\hline Tombol Beli Saham Syariah & $\begin{array}{l}\text { Masuk ke link pembelian saham } \\
\text { Syariah }\end{array}$ & $\checkmark$ & \\
\hline Tombol Wakaf & $\begin{array}{l}\text { Masuk ke halaman pengisian data } \\
\text { untuk melakukan wakaf uang }\end{array}$ & $\checkmark$ & \\
\hline Tombol Info Saham Syariah & Masuk ke info saham Syariah & $\checkmark$ & \\
\hline Tombol Simpan & Menyimpan hasil data & $\checkmark$ & \\
\hline Tombol Detail & Melihat lebih detail data & $\checkmark$ & \\
\hline Tombol Buat Saham CWLS Baru & $\begin{array}{l}\text { Masuk ke halaman membuat saham } \\
\text { Syariah }\end{array}$ & $\checkmark$ & \\
\hline Tombol Daftar & Mendaftar suatu data registrasi & $\checkmark$ & \\
\hline Tombol Isi Saldo & Mengisi saldo akun & $\checkmark$ & \\
\hline Tombol Kirim & Mengirim saldo akun & $\checkmark$ & \\
\hline Tombol Terima & Menerima saldo akun & $\checkmark$ & \\
\hline Tombol Lihat Semua & $\begin{array}{l}\text { Melihat riwayat keterangan saldo } \\
\text { akun }\end{array}$ & $\checkmark$ & \\
\hline
\end{tabular}


Pada tabel 1 dan 2 dapat terlihat bahwa hasil pengujian menggunakan Beta testing terhadap aplikasi android dan website berfungsi $100 \%$ dan tidak adanya kegagalan fungsi. Oleh sebab itu dapat disimpulkan bahwa aplikasi Wakaf Indonesia berfungsi sangat baik. Lalu pada hasil pengujian aspek functionality yang telah dilakukan oleh ahli bidangnya mendapatkan skor sebesar 95.5\% untuk aplikasi android dan 95.6\% untuk website sehingga dapat dilihat pada tabel 3 dan 4.

Tabel 3. Hasil Kelayakan Aplikasi Android Wakaf Indonesia oleh Ahli 1

\begin{tabular}{|c|c|c|}
\hline Aspek & Persentase & Keterangan \\
\hline Efektif & $95 \%$ & Sangat Layak \\
\hline Efisien & $94 \%$ & Sangat Layak \\
\hline Navigasi & $98 \%$ & Sangat Layak \\
\hline Desain & $93 \%$ & Sangat Layak \\
\hline Animasi & $97 \%$ & Sangat Layak \\
\hline Kelayakan & $96 \%$ & Sangat Layak \\
\hline Rata-rata Persentase & $95.5 \%$ & Sangat Layak \\
\hline
\end{tabular}

Tabel 4. Hasil kelayakan aplikasi website Wakaf Indonesia oleh Ahli 2

\begin{tabular}{|c|c|c|}
\hline Aspek & Persentase & Keterangan \\
\hline Efektif & $90 \%$ & Sangat Layak \\
\hline Efisien & $97 \%$ & Sangat Layak \\
\hline Navigasi & $97 \%$ & Sangat Layak \\
\hline Desain & $98 \%$ & Sangat Layak \\
\hline Animasi & $99 \%$ & Sangat Layak \\
\hline Kelayakan & $93 \%$ & Sangat Layak \\
\hline Rata-rata Persentase & $95.6 \%$ & Sangat Layak \\
\hline
\end{tabular}

Pada tabel 3 dan 4 adalah hasil tingkat kelayakan dari aplikasi yang akan dibangun oleh penilaian kedua ahli, dari hasil kelayakan menurut penilaian yang dilakukan oleh ahli blockchain mendapatkan hasil $95.5 \%$ untuk kelayakan pada aplikasi android dan 95.6\% untuk website. Sementara itu, Untuk tabel 5 dan 6 merupakan hasil dari pengujian aspek pada bagian portability dan pada aplikasi android didapatkan hasil aplikasi yang dapat beroperasi pada android versi 5.0 sampai 11. Dan untuk website telah dibuat sehingga dapat berjalan pada beberapa jenis browser dan tab, sehingga responsory ukuran website telah disesuaikan untuk setiap bagiannya.

Tabel 5. Hasil Pengujian Aspek Portability pada Aplikasi Android

\begin{tabular}{ll}
\hline \multicolumn{1}{c}{ Aspek } & Keterangan \\
\hline Android 11 & Berjalan \\
Android 10 & Berjalan \\
Android 9 Pie & Berjalan \\
Android 8.0 Oreo & Berjalan \\
Android 7.0 Nougat & Berjalan \\
Android 6.0 Marshmallow & Berjalan \\
Android 5.0 Lollipop & Berjalan \\
\hline
\end{tabular}


Tabel 6. Hasil Pengujian aspek Portability pada Website

\begin{tabular}{|c|c|}
\hline Aspek & Keterangan \\
\hline Goggle Chrome & Berjalan \\
\hline Safari & Berjalan \\
\hline Internet Explorer & Berjalan \\
\hline Mobile & Berjalan \\
\hline Tab & Berjalan \\
\hline Opera & Berjalan \\
\hline Firefox & Berjalan \\
\hline
\end{tabular}

Tabel 7. Hasil Pengujian aspek Usability pada aplikasi Android oleh Commissioner Badan Wakaf Indonesia

\begin{tabular}{lcc}
\hline & Aspek & Keterangan \\
\hline Tampilan & $94 \%$ \\
Manfaat & $98 \%$ \\
Kemudahan & $90 \%$ \\
Rata-Rata Skor & $\mathbf{9 4 \%}$ \\
\hline
\end{tabular}

Tabel 8. Hasil Pengujian aspek Usability pada website oleh Commissioner Badan Wakaf Indonesia

\begin{tabular}{lcc}
\hline & Aspek & Keterangan \\
\hline Tampilan & $94 \%$ \\
Manfaat & & $90 \%$ \\
Kemudahan & $80 \%$ \\
Rata-Rata Skor & $\mathbf{8 8 \%}$ \\
\hline
\end{tabular}

Dapat dilihat pada tabel 7 dan 8 merupakan nilai dari pengujian aspek usability yang akan digunakan langsung oleh pihak Badan Wakaf Indonesia sehingga penilaian dilakukan oleh pihak Badan Wakaf Indonesia yaitu oleh bapak Imam Nur Aziz, dapat diperhatikan pada usability aplikasi android mendapatkan nilai sebesar $94 \%$ dan $88 \%$ untuk website. Maka pada seluruh pengujian yang telah dilakukan, dapat dilihat bahwa program atau aplikasi yang akan dibangun telah sesuai dengan apa yang Badan Wakaf Indonesia inginkan, dan dari system sampai tampilan telah disetujui oleh pihak Badan Wakaf Indonesia dan Telkom Indonesia.

\section{Pembahasan}

Pada hasil kuisioner yang telah dilakukan dapat dikatakan bahwa aplikasi yang dibangun ini layak dikembangkan, dan perbedaan dari penelitian sebelumnya yaitu penyimpanan dari aplikasi masih menggunakan metode penyimpanan biasa yang rentan terhadap kecurangan dan juga kehilangan. Terdapat keterbatasan dari penelitian sebelumnya disebutkan bahwa salah satu keterbatasan pada penelitian tersebut adalah keterbatasan database sehingga data yang digunakan merupakan data tahun terakhir yang dapat diakses (Berakon \& Irsad, 2017).

Menggunakan teknologi penyimpanan blockchain, data dapat tersimpan dengan kekal dan juga sangat sukar untuk di retas ataupun di ubah. Sehingga aplikasi sejenis ini akan lebih baik jika dikembangkan lebih pesat lagi dan akan banyak membantu dalam hal transkip penyimpanan data. Sesuai dengan metode waterfall yang telah digunakan dan melihat perbandingan dari aplikasi serupa maka dapat dikatakan bahwa temuan ini relevan dengan 
apa yang diinginkan pihak Badan Wakaf Indonesia dan dapat dilihat dari hasil perhitungan pada tabel sebelumnya bahwa aplikasi ini sangat layak dibangun dan dikembangkan.Terlebih dengan beta testing dan alpha testing yang telah dilakukan sehingga dapat meningkatkan keakuratan dan kelayakan aplikasi ini apakah relevan dengan kebutuhan atau tidak, dan dari hasil yang dihasilkan bahwa aplikasi ini sangat layak.

\section{SIMPULAN}

Pembangunan aplikasi Wakaf Indonesia menggunakan metode Blockchain untuk memudahkan dalam transaksi saldo pada aplikasi ini dan pencatatan transaksi yang secara massal dilakukan akan menjaga keamanan. Hasil pengujian yang digunakan mendapatkan hasil total 95\% dengan kriteria sangat layak. Dengan metode penyimpanan yang lebih jelas dan kemampuan tidak dapat merubah data sehingga metode blockchain ini dapat dikembangkan untuk aplikasi lainnya. Dalam aplikasi wakaf ini akan selalu dikembangkan dalam hal pembayaran ataupun sistem berwakaf yang lebih mudah sehingga semua bisa dilakukan secara online tanpa harus datang langsung ke lembaga wakaf. Dengan dibangunkan aplikasi wakaf ini menjadi salah satu pacuan untuk aplikasi lainnya yang berada di Indonesia dapat dikembangkan dengan metode blockchain.

\section{REFERENSI}

Anam, M. K., \& Anwar, R. (2020). Penerapan Aplikasi Pendukung Touring pada Komunitas Motor Berbasis Android. Edumatic: Jurnal Pendidikan Informatika, 4(1), 1-10. https://doi.org/10.29408/edumatic.v4i1.1980

Ayed, A. Ben. (2017). A conceptual secure blockchain-based electronic voting system. International Journal of Network Security \& Its Applications, 9(3), 1-9.

Berakon, I., \& Irsad, A. M. (2017). E-Payment: Inovasi Layanan Penghimpunan Dan Redistribusi Wakaf Uang Berbasis Online Dalam Percepatan Pembangunan Ekonomi Indonesia. Jurnal Al-Qardh, 2(1), 26-41. https://doi.org/10.23971/jaq.v2i1.824

Caldiroli, C. L., Garbo, R., Pallavicini, F., Antonietti, A., Mangiatordi, A., \& Mantovani, F. (2017). How web design influences user experience: A multi-modal method for realtime assessment during web browsing. 2017 14th IEEE Annual Consumer Communications \& Networking Conference (CCNC), 1063-1066. https://doi.org/10.1109/CCNC.2017.7983286

Fahmi, A., Sugiarto, E., Winarno, A., Sumpeno, S., \& Purnomo, M. H. (2018). Waqf Lands Assets Classification Based On Productive Value For Business Development Using Naïve Bayes. 2018 International Seminar on Research of Information Technology and Intelligent Systems (ISRITI), 622-626. https://doi.org/10.1109/ISRITI.2018.8864489

Fahmi, A., Sugiarto, E., Winarno, A., Sumpeno, S., Purnomo, M. H., Nakasumi, M., Huang, S. (2017). Application of Block Chain Technology in Power Information Asset Lifecycle Management. 2006 ITI 4th International Conference on Information \& Communications Technology, 01, 435-441. https://doi.org/10.1109/SIET.2017.8304178

Feng, Q., He, D., Zeadally, S., Khan, M. K., \& Kumar, N. (2019). A survey on privacy protection in blockchain system. Journal of Network and Computer Applications, 126, $45-58$.

Huang, J., Kong, L., Chen, G., Wu, M.-Y., Liu, X., \& Zeng, P. (2019). Towards secure industrial IoT: Blockchain system with credit-based consensus mechanism. IEEE Transactions on Industrial Informatics, 15(6), 3680-3689.

Judmayer, A., Stifter, N., Krombholz, K., \& Weippl, E. (2017). Blocks and chains: introduction to bitcoin, cryptocurrencies, and their consensus mechanisms. Synthesis Lectures on Information Security, Privacy, \& Trust, 9(1), 1-123.

Lee, D. (2007). Hash Function Vulnerability Index and Hash Chain Attacks. 2007 3rd IEEE 
Workshop on Secure Network Protocols, 1-6. https://doi.org/10.1109/NPSEC.2007.4371616

Muzammal, M., Qu, Q., \& Nasrulin, B. (2019). Renovating blockchain with distributed databases: An open source system. Future Generation Computer Systems, 90, 105-117.

Nakasumi, M. (2017). Information Sharing for Supply Chain Management Based on Block Chain Technology. 19th Conference on Business Informatics (CBI), 01, 140-149. https://doi.org/10.1109/CBI.2017.56

Pinandito, A., Az-zahra, H. M., Fanani, L., \& Putri, A. V. (2017). Analysis of web content delivery effectiveness and efficiency in responsive web design using material design guidelines and User Centered Design. International Conference on Sustainable Information Engineering and Technology (SIET), 435-441. Indonesia: IEEE. https://doi.org/10.1109/SIET.2017.8304178

Rohmaningtyas, N. (2017). The significance of waqf in historical and teoritical studies. Journal of Islamic Economics Science, 1(1), 39-55.

Yu, W., \& Huang, S. (2018). Traceability of Food Safety Based on Block Chain and RFID Technology. 11th International Symposium on Computational Intelligence and Design (ISCID), 01, 339-342. China: IEEE. https://doi.org/10.1109/ISCID.2018.00083

Zhang, J., Li, Y., Zhao, M., Zhang, C., \& Ma, J. (2019). Application of Block Chain Technology in Power Information Asset Lifecycle Management. 2019 2nd International Conference on Information Systems and Computer Aided Education (ICISCAE), 6-9. China: IEEE. https://doi.org/10.1109/ICISCAE48440.2019.221577 